\title{
Instantaneous Assessments of Left Ventricular Dimensions by Ultrasonic Analogue Conversion System
}

\section{An Experimental Study}

\author{
Yasumi Uchida, M.D., Kiyoshi Inoue, M.D., and \\ Nobuo Yoshimoto, M.D.
}

\begin{abstract}
SUMMARY
A new time-to-voltage analogue converter of ultrasound echo was made. The converter samples the echoes from the septal endocardium and the endocardium of the posterior wall of the left ventricle. The converter also enables automatic calculates left ventricular minor axis, volume, and work. In fixed human hearts, the left ventricular minor axis and volume calculated by the converter were close to the actual ones. In anesthetized dogs, left ventricular minor axis, volume, ejection fraction and stroke work calculated by the converter were close to those calculated by cineventriculography. The results indicate applicability of the ultrasonic analogue converter for instantaneous assessments of left ventricular dimensions and function.
\end{abstract}

\section{Additional Indexing Words :}

Analogue converter Fixed human hearts Dog hearts Cineventriculography

HE ability to estimate left ventricular dimensions and function by echo-
cardiography was established by Feigenbaum, Popp, Fortuin, and Pombo, ${ }^{1-6)}$ The echoes from the left ventricle are usually photographed on fixed or moving films. Although photographic method of recording enables movements of several tissues to be studied simultaneously, it is time-consuming to assess quantitatively and instantaneously the motion of a given tissue or dimension from the conventional photographic records. In order to avoid this shortcoming, direct and instantaneous recording of the motion of a given tissue by time-to-voltage analogue converter was established by Effert, Wells, Ross, and Uchida. ${ }^{7-9)}$ Since the converter made by them could record only one echo, dimensions such as left ventricular minor axis could not be obtained.

From the Second Department of Internal Medicine, Faculty of Medicine, University of Tokyo, Hongo, Tokyo 113, Japan.

Received for publication March 26, 1976. 
We devised an analogue conversion system which can select 2 echoes simultaneously; one echo from the septal surface of the left ventricle and another from the endocardial surface of the left ventricular posterior wall. This system also calculates instantaneously and automatically not only the left ventricular minor axis but also the left ventricular volume and work. We report the applicability of this analogue conversion system for assessments of left ventricular dimensions in fixed human hearts and those in dog hearts.

\section{Materials and Methods}

1. Ultrasonic analogue conversion system

The refractor echo was presented in the form of an amplitude-modulated timebase on an A-scope. At the same time, the echo was displayed on a brightnessmodulated time-base, the B-scope. Successive 2 gating signals were produced at $820 \mathrm{~Hz}$ and were displayed on the A-scope (Fig. 1). The position and width of the gating signals were changed manually.

Gate A:

The first gate (gate A in Fig. 1) sampled the downstorke of the echo within the gating pulse. When there ware more than 2 echoes within the gate, the gate sampled the downstroke of the first echo within the gate. Sampling point of the downstroke of the echo was changed by changing the threshold. Usually, the sampling point was set close to the beginning of the downstroke. A square-wave sampling pulse 0.5 microsec in duration was generated at the sampling point of the echo. A segment of the saw-teeth wave which was generated simultaneously with the gating pulse, was sampled during the sampling pulse was generated. The sampled segment of the wave was maintained to the next sampling pulse (Fig. 2). The voltage of the sampled segment of the saw-teeth wave corresponded to the distance from the transducer to the sampled point of the refractor. The train of the sampled segments of the saw-teeth waves was smoothed by a $15 \mathrm{~Hz}$ filter. The sampling pulse was differentiated and clamped to provide a signal with brightness-modulated beam on the A-scope display with a delay of 0.5 microsec in range to the sampled point. Thus, it was possbile to identify the sampled point of the echo (Figs. 1 and 2).

Gate B:

The second gate (gate B in Fig. 1) sampled the upstroke of the echo within the gate. When there were more than one echo within the gate with a sufficient voltage, the upstroke of the first echo was sampled. The segment of the saw-teeth wave within the sampling pulse which was produced at the upstroke of the echowas sampled and was kept to the next sampling pulse. The voltage of the sampled segment of the saw-teeth wave corresponded to the distance from the transducer to the sampled point of the refractor. The train of the sampled segments of the sawteeth waves was smoothed by a $15 \mathrm{~Hz}$ filter and was recorded on a mingograph or pen-oscillograph. The sampling pulse was differentiated and clamped to provide a signal on the A-scope display as in the case of gate A (Figs. 1 and 2).

The voltage of the segments of the saw-teeth wave sampled by gate A was sub- 


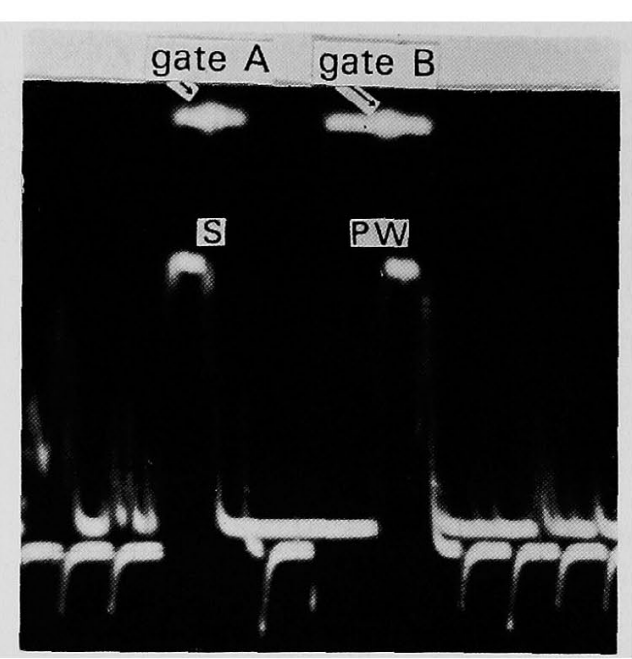

Fig. 1. The gate pulses (gate A and gate B), sampling signals (arrows) and the echoes from the fixed human left ventricle displayed on the A-scope. $\mathrm{S}=$ the interventricular septum. $\mathrm{PW}=$ posterior left ventricular wall.

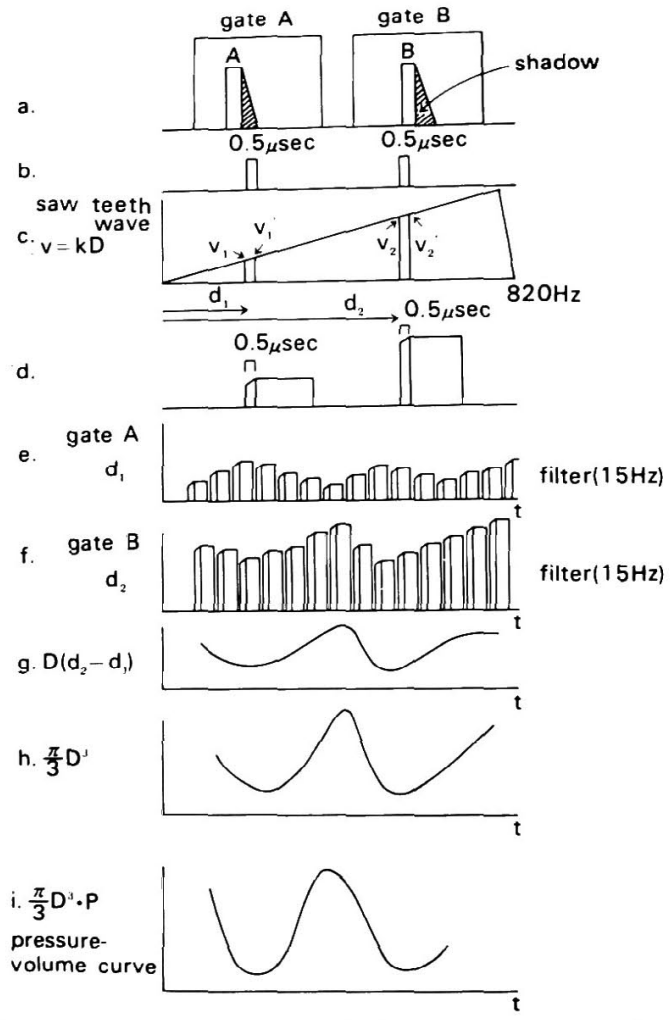

Fig. 2. Schematic representation of the process of sampling and calculation of the left ventricular dimensions and pressure-volume curve.

$d_{1}$ and $d_{2}=$ the distance from the echo-transducer to the sampling points. $\mathrm{D}=$ the distance between the 2 sampled points of the refractors (the minor axis in the case of left ventricle). $D^{3} / 3=$ left ventricular volume. For further detail, refer to the text. 

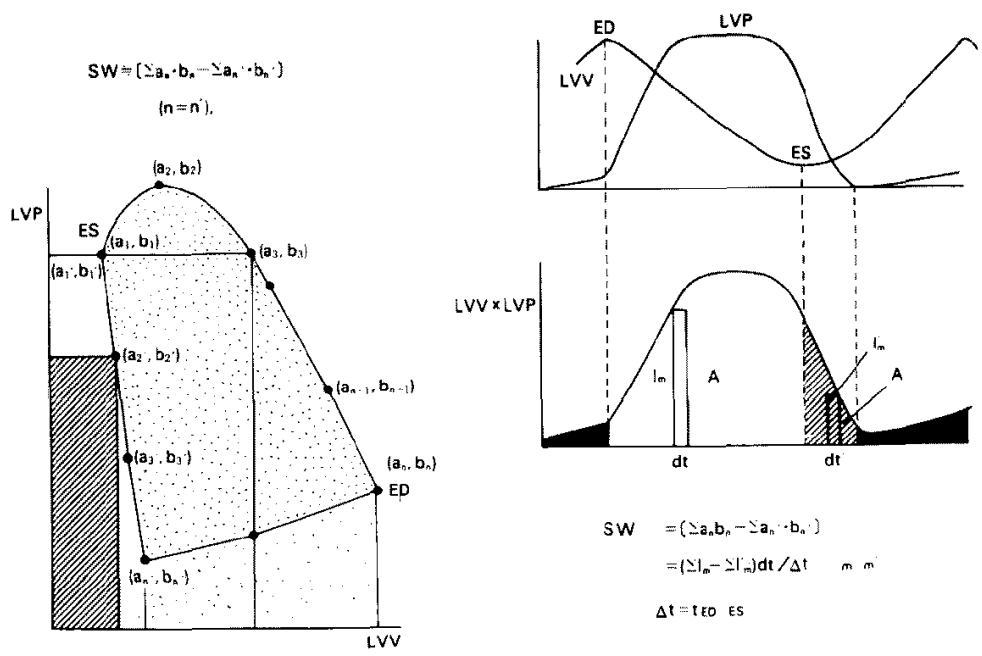

Fig. 3. Left half: a method to calculate total stroke work from pressure-volume loop constructed from cineventriculograms and left ventricular pressure.

Right half: a method to calculate total stroke work from the pressurevolume curve recorded by the conversion system. LVP=left ventricular pressure. $\quad t_{E D-E S}=$ the time from end-diastole to end-systole.

tracted automatically from that sampled by gate B. The output voltage thus obtained corresponded to the distance between the 2 sampled points. In this study, the echo from the septal surface of the left ventricle was sampled by gate $A$ and the echo from the endocardial surface of the left ventricular posterior wall was sampled by gate $\mathrm{B}$. The output voltage obtained by subtraction, therefore, corresponded to the minor axis of the left ventricle.

Left ventricular volume was calculated automatically by an integrated circuit of $\pi \mathrm{D}^{3} / 3$ ( $\mathrm{D}=$ minor axis) according to Popp and Feigenbaum. ${ }^{1), 2)}$ Left ventricular pressure-volume curve was also claculated automatically by a circuit of left ventricular pressure $\times$ calculated left ventricular volume. The left half of Fig. 3 indicates total stroke work obtained from the pressure-volume loop using left ventricular volume calculated from cineventriculogram and left ventricular pressure (dotted area). The right half of this figure indicates the method to calculate total stroke work from pressure-volume curve which was obtained by the analogue conversion system. In the right half of the figure, the area under the curve from the end-diastole to end-systole was divided into equal parts $(m)$. The area under the curve from the end-systole to the minimum left ventricular pressure was also divided into equal parts $\left(\mathrm{m}^{\prime}, \mathrm{m}=\mathrm{m}^{\prime}\right)$. The sum of the height $\left(\mathrm{I}^{\prime}\right)$ of the latter was subtracted from the sum of the height $(I)$ of the former. This corresponds to the dotted area multiplied by $t_{E D-E S}$ (the time from the enddiastole to end-systole).

\section{Calibration:}

The position and width of gate A and gate B were obtained from the voltages which corresponded to the distance from the transducer to the beginning and the end of the gating pulses and were recorded on a recorder using multivibraters which 
produced square-waves at $2 \mathrm{~Hz}$. At the same time, the position and width of the gates were digitally presented. Stepwise pulses, each of which corresponded to $1 \mathrm{~cm}$, were also produced for calibration of the minor axis of the left ventricle. At the same time, the stepwise pulses were triplicated by a circuit of $\pi \mathrm{D}^{3} / 3$ for volume calibration. For calibration of stroke work, pressure calibration signal was changed stepwise while volume calibration signal was unchanged, or vice versa.

2. Assessments of left ventricular volume using postmorten fixed human hearts

Eight fixed human hearts ( 4 normal, 2 combined valvular disease, and 2 concentric hypertrophy) were used for left ventricular volume measurements. The right and left ventricles were filled with stored human blood. The echo-transducer was located over a water-soluble sound transmission gel interface at the outflow wall of the right ventricle and angled toward the posterior wall of the left ventricle until the echoes from the anterior leaflet of the mitral valve, interventricular septum and the endocardial surface of the posterior left ventricular wall were encountered. The echoes from these portions were displayed on B-scope and were photographed. At the same time, the position and width of the gates and threshold were set to sample the echo from the septal surface of the left ventricle and the echo from the endocardial surface of the left ventricular posterior wall, and minor axis (D) and volume were calculated automatically by the method described above. A stainless steel needle was inserted from the left ventricular posterior wall through the interventricular septum to the center of the transducer to measure the actual distance between the interventricular septum and the endocardium of the left ventricular posterior wall. After measurement of the blood volume in the left ventricle, the left ventricular endocardium was painted with barium sulfate and ventriculography at right oblique, antero-posterior and lateral projections was performed to measure the left ventricular volume by the method of Sandler and Dodge. ${ }^{10}$ ) After ventriculography, the left ventricle was sectioned longitudinally to measure the actual longer axis (the distance from the aortic valve to the apex).

3. Assessments of left ventricular dimensions and function using the dog hearts

Nine dogs with intravenous pentobarbital sodium anesthesia $(35 \mathrm{mg} / \mathrm{Kg}$ ) were used for this study. The trachea was intubated for positive pressure respiration with air. The upper 7 ribs on the left side were removed. Two catheters were introduced into the left ventricle; one from the right common carotid artery for measurement of ventricular pressure and the another from the right femoral artery for injection of contrast material. The third catheter was introduced through the left femoral artery to the aortic root to measure aortic pressure.

The echo-transducer was placed on the outflow wall of the right ventricle and angled posteriorly until a plane was found which included the interventricular septum and the endocardial surface of the posterior wall of the left ventricle just below the anterior leaflet of the mitral valve. The echoes from these portions were displayed on the A- and B-scopes. In order to obtain the endocardial echoes sufficient enough for sampling by the converter, FTC of the A-scope was not used. The position and width of the gates and sampling threshold voltage were adjusted to sample the echoes from the septal surface and the endocardium of the left ventric- 
ular posterior wall and so as not to sample the echoes from the other tissues such as mitral leaflets (Fig. 1).

Septal wall motion (S), posterior wall motion (PW), minor axis (D), ventricular volume (LVV), and pressure-volume curve calculated by the converter were recorded with aortic and left ventricular pressures on a mingograph. Left ventricular end-diastolic volume (EDV), end-systolic volume (ESV), and ejection fraction (EF) were calculated from the records. Because of convenience for calculation of volume, volume curve was frequently recorded through $\log _{e}$ circuit. Endocardial mean $\left.\mathrm{V}_{\mathrm{cf}}\left(\mathrm{D}_{\mathrm{ED}}-\mathrm{D}_{\mathrm{ES}}\right) / \mathrm{ET} . \mathrm{D}_{\mathrm{ED}}\right)$ and normalized systolic ejection rate (EDV-ESV)/ ET. EDV) were calculated by the methods descrived by Quinones et al. ${ }^{11}$ The time from the beginning of the upstroke to dicrotic notch of the aortic pressure was used as ejection time (ET). Total stroke work (SW) was obtained from the pressure-volume curve. After recording left ventricular dimensions and pressure-volume curve by the analogue conversion system, cineventriculography was performed at right oblique projection using $35 \mathrm{~mm}$ cinefilms at $80 \mathrm{flame} / \mathrm{scc}$. Cineventriculograms thus obtained were used for calculation of minor axis and volume by arealength method, ${ }^{12)}$ endocardial mean $V_{\mathrm{cf}}$, systolic ejection rate and total stroke work using pressure-volume loop. ${ }^{13)}$ In order to obtain pressure-volume loop, Xray exposure signals were recorded with aortic and left ventricular pressures.

\section{REsults}

1. Left ventricular dimensions of fixed human hearts

The distance from the surface of the interventricular septum to the endocardial surface of the posterior left ventricular wall, the minor axis (D), measured by the converter was close to the actual distance. Also the distance calculated from the conventional photographic records was close to the actual distance as shown in Fig. 4. Although not significant, the distance calculated from the photographic records was somewhat shorter than that calculated by the converter. The longer axis $(L)$ calculated by the converter and that calculated from the photographic records using the formula of $2 \mathrm{D}$ were smaller than the actual one in the hearts of large left ventricular volume, although there were high correlation coefficients among them (Fig. 4). Left ventricular volume calculated by the converter was close to the actual one and there was a high correlation coefficient between them. The volume calculated from the photographic records was somewhat smaller than the actual one and that calculated by the converter (the middle of Fig. 4). The left ventricular volume calculated by the method of Sandler and Dodge using ventriculograms was more close to the actual one than that calculated by the converter. The volume calculated from the ventriculograms obtained at right oblique projection was somewhat larger than the actual one (the right end of Fig. 4). 
2. Left ventricular dimensions and function in dogs

In Fig. 1, shows echoes from the interventricular septum and the posterior left ventricular wall displayed on the A- scope. In Fig. 5, shows instantaneous changes in septal wall motion, posterior wall motion, minor axis, volume
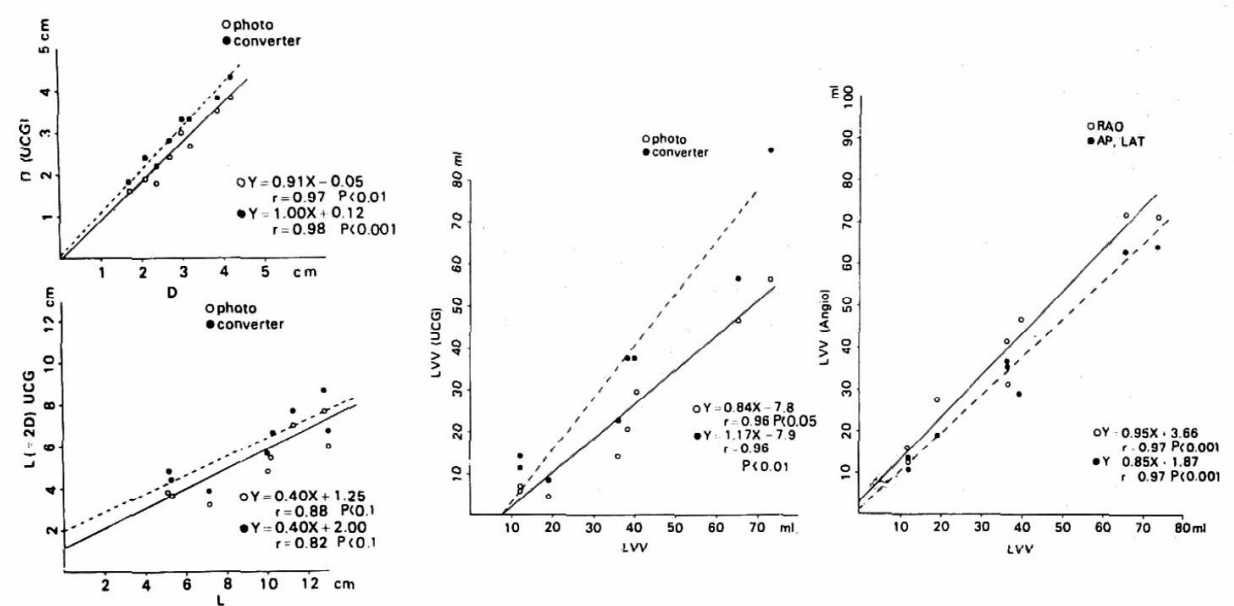

Fig. 4. Minor axis (D), longer axis (L), and left ventricular volume (LVV) of the fixed human hearts. Converter=ultrasonic conversion system. Photo $=$ photographic records of $\mathrm{B}$-mode display, $\mathrm{RAO}=\mathrm{X}$-ray ventriculography at right anterior oblique projection. AP, LAT $=\mathrm{X}$-ray ventriculography at antero-posterior and lateral projections.

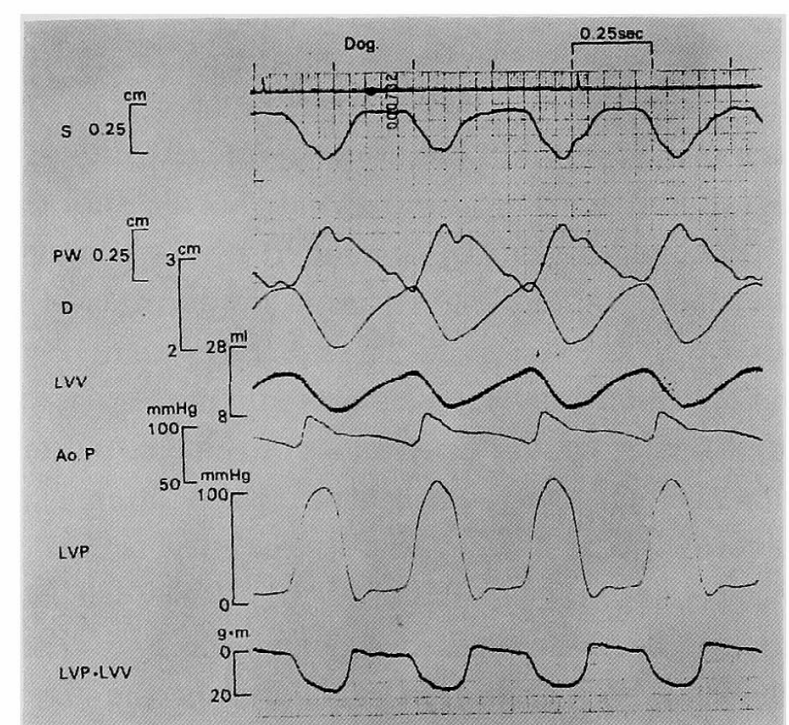

Fig. 5. From the top: interventricular wall motion (S), posterior left ventricular wall motion $(\mathrm{PW})$, minor axis $(\mathrm{D})$, left ventricular volume through a $\log _{\mathrm{e}}$ circuit (LVV), aortic pressure (Ao. P), left ventricular pressure (LVP), and pressure-volume curve. Upside down recording of the pressure-volume curve due to the character of the conversion system. 

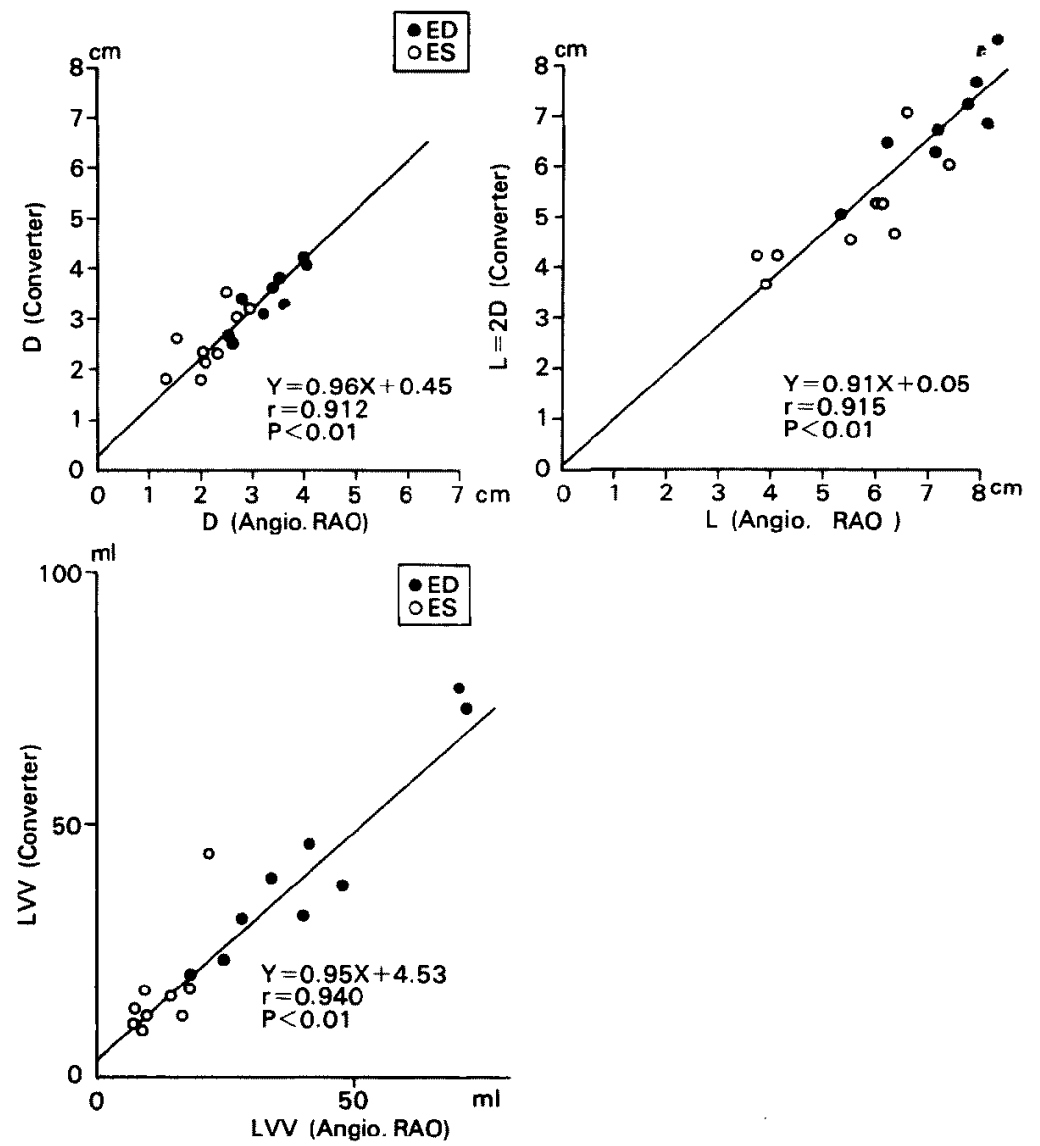

Fig. 6. Left ventricular minor axis (D), longer axis (L), and left ventricular volume ( $\mathrm{LVV}$ ) obtained from 9 dogs. Angio= cineventriculography. $\mathrm{ED}=$ end-diostole. $\mathrm{ES}=$ end-systole.

(recorded through $\log _{e}$ circuit), pressure-volume curve, and their relation to aortic and left ventricular pressures. In Fig. 6, shows left ventricular minor axis, longer axis, and volume calcualted by the converter and their rclation to those calculated from the cineventriculograms. The minor axis calculated automatically by the converter was close to that calculated from the cineventriculograms. Also, longer axis calculated using the formula of $2 \mathrm{D}$ and left ventricular volume obtained by the converter were close to those calculated from the cineventriculograms. Although ejection fraction and stroke work calculated from the records obtained by the converter were close to those calculated from the cineventriculograms, endocardial mean $V_{c f}$ and systolic ejection rate calculated from the records of converter were smaller than those calculated from the cineventriculograms (Fig. 7). 

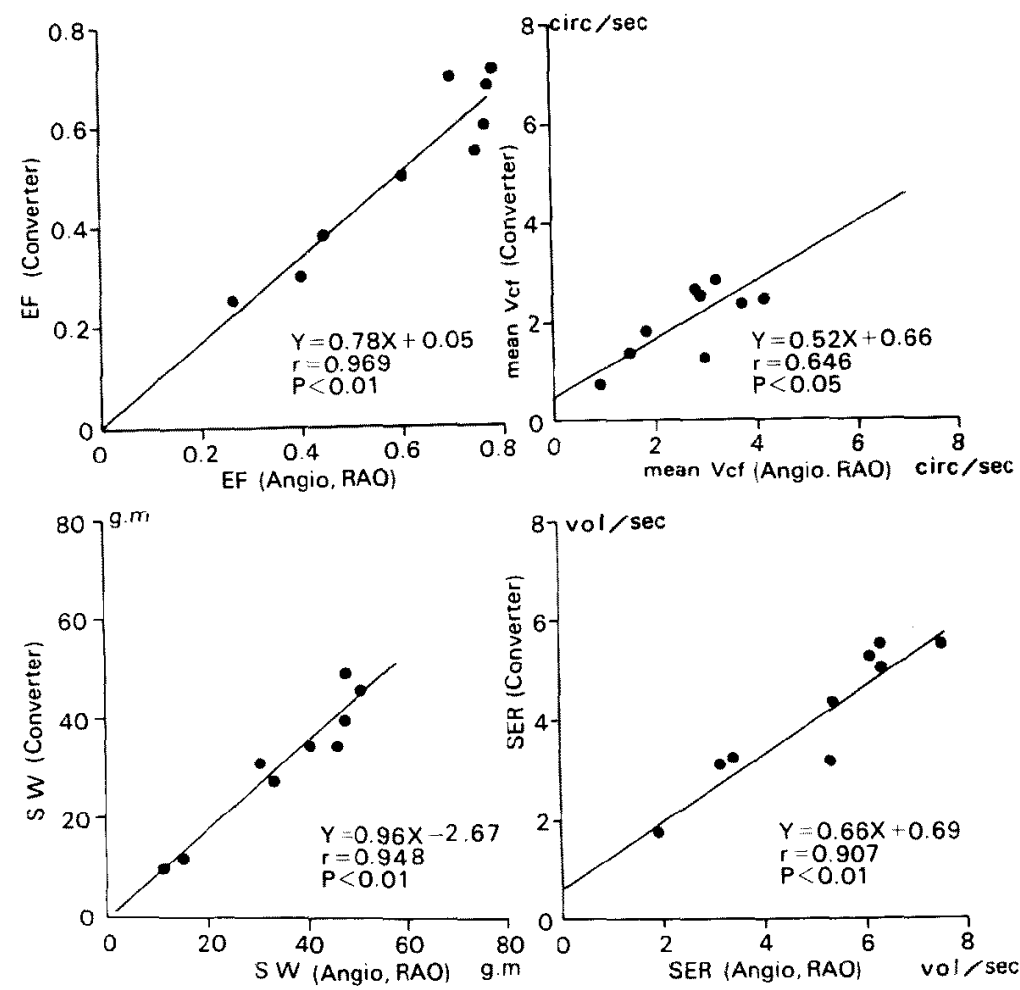

Fig. 7. Ejection fraction (EF), mean rate of endocardial circumferential fiber shortening (mean $\mathrm{V}_{\mathrm{ef}}$ ), total stroke work (SW), and systolic ejection rate (SER) obtained from the same dogs.

\section{Drscussion}

Since the studies by Feigenbaum, Popp, and Fortuin, ${ }^{1)-5)}$ numerous studies on assessments of left ventricular dimensions and function by ultrasound have been reported and clinical applicability of this method has been discussed. ${ }^{-4), 15)}$ Although conventional photographic recording of B-mode display can record more than one echo simultaneously, it is time-consuming to calculate instantaneous changes in left ventricular wall motion and dimensions by this method as in the case of cineventriculography. In order to avoid this shortcoming, instantaneous assessments of left ventricular minor axis by echo-videodensitometry has been proposed.16) The ultrasonic analogue conversion system in this study was also made to avoid this shortcoming.

The shortcoming of analogue conversion is the possibility that the converter may sample the echoes from the choldae and the mitral leaflets which entere into the gates with a voltage of above the sampling threshold and that 
the converter may not sample the echo from the endocardial surface when it's voltage is below sampling threshold. In order to avoid these miss-sampling, monitoring of the B-mode display, display without FTC on the A-scope and adjustment of the position and width of the gates were required in this study.

In fixed human hearts, the minor axis and volume calculated by the converter were close to the actual ones and also close to those calculated from the conventional photographic records, although those calculated from ventriculography were more close to the actual ones. This fact indicates applicability of analogue conversion system for assessments of left ventricular minor axis and volume in fixed human hearts. The longer axis of the left ventricle calculated by the formula of $2 \mathrm{D}$ was shorter than the actual ones as has been reported by several workers.

In anesthetized dogs, minor axis and longer axis calculated by the converter were close to those calculated from the cineventriculograms using arealength method. The difference in shape of the left ventricle between the fixed human heart and the dog heart and underestimation of the longer axis of the dog left ventricle by cineventriculography may have been the reason for close correlation between the longer axis calculated by the converter and that calculated from cineventriculograms in dogs and less close correlation in fixed human hearts. Left ventricular volume, ejection fraction and total stroke volume claculated from the records of the converter were also close to those calculated from cineventriculograms. However, the values of endocardial mean $V_{c f}$ and systolic ejection rate calculated from the records of the converter were smaller, especially in larger left ventricle, than those calculated from cineventriculograms. The difference in the portion of the ventricle from which changes in minor axis was calculated may have contributed to the difference in the values of endocardial mean $V_{c f}$, and the regional difference in ventricular wall motion may have contributed to the difference in the values of systolic ejection rate.

Nevertheless, the ultrasonic analogue conversion system used in this study is applicable for instantaneous assessments of left ventricular dimensions and work if the direction of the echo-transducer is appropriately adjusted and the position and width of the gates and sampling threshold are adjusted so as not to sample the echoes from elsewhere than the endocardial surfaces.

\section{References}

1. Feigenbaum H, Zaky A, Nasser WK: Use of ultrasound to measure left ventricular volume. Circulation 35: 1092, 1967

2. Feigenbaum $\mathbf{H}$, Wolfe SB, Popp $\mathbf{R}$ et al: Correlation of ultrasound with angiography in 
measurement of left ventricular diastolic volume. Am J Cardiol 23: 111, 1969

3. Popp RL, Wolfe SB, Hirata $\mathrm{T}$ et al: Estimation of right and left ventricular size by ultrasound. Am J Cardiol 24: 523, 1969

4. Fortuin NJ, Hood WP Jr, Sherman ME et al: Determination of left ventricular volume by ultrasound. Circulation 44: 575, 1971

5. Fortuin NJ, Hood WP Jr, Craige E: Evaluation of left ventricular function by echocardiography. Circulation 46: 26, 1972

6. Pombo JR, Troy BL, Russel RO Jr: Left ventricular volumes and ejection fraction by echocardiography. Circulation 43: 493, 1971

7. Effert S, Hertz CH, Böhme W: Direkte Registrierung des Ultraschallkardiograms mit dem Elektrokardiographen. Z Kreislaufforsch 48: 230, 1959

8. Wells PNT, Rass FGM: A time-to-voltage analogue converter for ultrasonic cardiology. Ultrasonics 7: 171, 1969

9. Uchida $\mathrm{Y}$, Inoue $\mathrm{K}$, Ueda $\mathrm{K}$ et al: Selective recording of the echos from mitral valve and left ventricular posterior wall by analogue gate. Saishinigaku 28: 583, 1973 (in Japanese).

10. Dodge HT, Sandler $\mathbf{H}$, Baxley WA, et al.: Use of biplane angiography for measurement of left ventricular volume in man. Am Heart J 60: 762, 1960.

11. Quinoes MA, Gaasch WH, Alexander JK: Echocardiographic assessment of left ventricular function. Circulation 50:42, 1974

12. Greene DG, Carlisle R, Grant $\mathrm{C}$ et al: Estimation of left ventricular volume by one-plane cineangiography. Circulation 35: 61, 1967

13. Jarmakani MM, Edwards BS, Spach MS et al: Left ventricular pressure-volume characteristic in congenital heart disease. Circulation 37: 879, 1968

14. Murray JA, Johnston W, Reid JM: Echocardiographic determination of the left ventricular dimensions, volume and performance. Am J Cardiol 30: 252, 1972

15. Redwood DR, Henry WL, Epstein SE: Evaluation of the ability of echocardiography to measure acute alteration in left ventricular volume. Circulation 50: 901, 1974

16. Gibson DG, Brown D: Measurement of instantaneous left ventricular dimensions and filling rate in man using echocardiography. Brit Heart J 35: 1141, 1973 